\title{
Cause versus effect? Tricuspid valve replacement in the management of a failing Fontan circulation
}

\author{
S. Adil Husain, MD
}

\footnotetext{
From the Section of Pediatric Cardiothoracic Surgery, Department of Surgery and Pediatrics Chief, Heart Center Primary Children's Hospital, Intermountain Healthcare, University of Utah Health, Salt Lake City, Utah. Disclosures: Author has nothing to disclose with regard to commercial support.

Received for publication April 9, 2018; accepted for publication April 10, 2018; available ahead of print May 16, 2018.

Address for reprints: S. Adil Husain, MD, Professor, Department of Surgery and Pediatrics, Chief, Section of Pediatric Cardiothoracic Surgery, Co-Director, Heart Center Primary Children's Hospital, Intermountain Healthcare, University of Utah Health, 100 N Mario Capecchi Dr, Suite 2200, Salt Lake City, UT 84113 (E-mail: adil. husain@hsc.utah.edu).

J Thorac Cardiovasc Surg 2018;156:e145-6

$0022-5223 / \$ 36.00$

Copyright (c) 2018 by The American Association for Thoracic Surgery

https://doi.org/10.1016/j.jtcvs.2018.04.043
}

Management of single-ventricle physiology after completion Fontan continues to produce improved outcomes and transplant-free quality of life metrics. Single-ventricle survivorship clinics and other focused care delivery models within congenital heart programs provide multidisciplinary care across all medical components of need for these complex patients. ${ }^{1}$ Despite these advances, however, transplantation remains a common end pathway for these palliated patients. Creation of a medical and social environment that is best for patients to prepare for this "final" surgical stage confounds even the most advanced institutions.

Failure of the right ventricle in patients with hypoplastic left heart syndrome (HLHS) evolves across varying time courses, may be associated with anatomic anomalies such as arch obstruction or atrioventricular valve regurgitation, and is severely confounded by electrophysiologic abnormalities. In this issue of the Journal, Perrier and colleagues ${ }^{2}$ from Royal Children's Hospital in Melbourne present a fascinating case report of a 6-year-old child who was seen with sudden RV failure 2 months after successful extracardiac completion Fontan. Because of psychosocial challenges with autism, that patient was not deemed a suitable candidate for either mechanical support or transplantation. He was found to have severe tricuspid valve regurgitation. The group describes an initial unsuccessful attempt at valvular repair, with associated heart block and need for postcardiotomy extracorporeal mechanical support. The patient then underwent valve replacement with a bioprosthesis. After successful discharge within a palliative care pathway, the patient remarkably had right ventricular recovery and a return of sinus rhythm at 9 months and 3.5 years, respectively.

Perrier and colleagues ${ }^{2}$ provide us with a valuable lesson, as well as a set of insightful questions. First, the gift of transplantation is often the final common pathway in the treatment of HLHS. However, programs must be strategic in

\section{References}

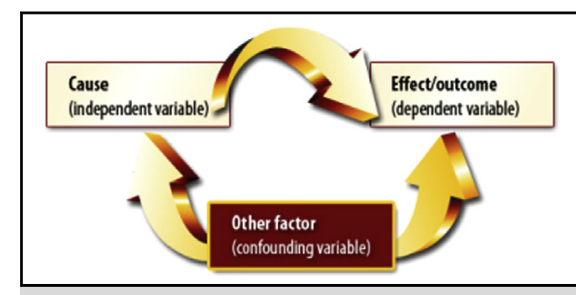

Cause versus effect. Can management of the effect alter the course of the cause?

Central Message

Acute RV failure after completion Fontan creates profound management challenges. Although transplantation is often the final surgical pathway, alternative approaches may prove to be successful.

See Article page e141.

truly exhausting each potential mode of therapy before submitting the patient to this pathway. Had this child not had autism, he may not have benefited from the approach outlined. In hindsight, he has now gained several valuable years before the potential need for an allograft. Second, in children with HLHS, is sudden deterioration of right ventricular function perhaps more common than we report? Single right ventricle morphology has long been associated with worse long-term outcomes. ${ }^{3}$ Although one may believe tricuspid valve regurgitation to be the effect of right ventricular dilation, and as such not amenable to intervention, are there instances in which this is not the case? For this patient, a competent tricuspid valve led to eventual right ventricular recovery. Why did surgical intervention on the effect actually benefit the proposed cause? A more mindful approach to what truly is cause and what is effect within this unique patient population, as well as refocusing our thoughts on the potential additional pathways of surgical intervention before transplantation, might benefit these children and families immensely. In the field of congenital heart surgery, we should embrace the gift of an unpredicted positive outcome with the same vigor that we critique our failures and unfortunate losses. Our field mandates humility and perseverance, especially as we continue to evolve in our treatment strategies for HLHS.

1. Rychik J. The relentless effects of the Fontan paradox. Semin Thorac Cardiovasc Surg Pediatr Card Surg Annu. 2016;19:37-43. 
2. Perrier SL, Zhu MZ, Weintraub RG, Konstantinov IE. Tricuspid valve replacement in failing Fontan circulation with severe ventricular dysfunction: the road not taken? J Thorac Cardiovasc Surg. 2018;156:e141-3.
3. Feinstein JA, Benson DW, Dubin AM, Cohen MS, Maxey DM, Mahle WT, et al. Hypoplastic left heart syndrome: current considerations and expectations. J Am Coll Cardiol. 2012;59(1 Suppl):S1-42. Erratum in: J Am Coll Cardiol. 2012;59:544. 